\title{
Digital Interpretation of the Zhuxian Town Woodcut New Year Paintings Under the Background of Industrialization
}

\author{
Hui $\mathrm{Li}$ \\ School of Art and Design \\ Huanghe Science and Technology College \\ Zhengzhou, Henan, China 450063
}

\begin{abstract}
The Zhuxian Town woodcut new year paintings as the originator of Chinese woodblock new year pictures, not only have a long history, but also have a distinctive artistic style which can be described as a treasure of Chinese traditional culture. In the contemporary era, to carry out industry development with the digital painting technology is an important channel to promote the inheritance and development. In view of this, this paper describes the overview of Zhuxian Town woodcut new year paintings, analyzes the necessity of the digital interpretation, and puts forward some specific suggestions.
\end{abstract}

Keywords-cultural industrialization; Zhuxian Town woodcut new year paintings; digital interpretation; research and analysis

\section{THE BRIEF INTRODUCTION TO ZHUXIAN TOWN WOODCUT NEW YEAR PAINTINGS}

Zhuxian Town is located in Kaifeng City, Henan Province, which is one of the birthplaces of Chinese new year paintings art. The picture composition is full, the lines extend roughly and concisely, the shapes are simple and exaggerated, the color is fresh and gorgeous. It is said to be four Chinese New Year paintings together with Tianjin Yangliuqing New Year paintings, Weifang Yangjiabu woodcut New Year paintings, Jiangsu Taohuawu New Year paintings. Since Tang Dynasty, Zhuxian Town began making pictures, after the development in Song and Yuan Dynasties, to Qing Dynasty ushered in the peak of the development. During the period of the Republic of China, affected by the wars and other aspects, Zhuxian Town woodcut New Year paintings got into the unprecedented low tide. Until after the founding of new China, it had recovered. But short-lived, in the 1960s and 1970s, influenced by political, Zhuxian Town woodcut New Year paintings once stagnated. After the reform and opening up, along with the development of economy, politics and culture, the Zhuxian Town woodcut New Year paintings also Rejuvenated, at the same time, it suffered the collision of traditional culture and modern culture. After entering the new century, it has gradually faded out of the common people's vision, lost the original value and broad market, once to a precarious position. Therefore, to promote the industrialization development by means of digital technology, has become an important channel and means of its heritage.

\section{The MEANING OF Digital INTERPRETATION OF ZHUXIAN TOWN WOODCUT NEW YeAR PAINTINGS}

\section{A. Digital Interpretation Is the Basis of Promoting Its Industrialization}

The industrialization development of Zhuxian Town woodcut New Year paintings shall take the full census, carding and integration as the basis, to develop the fittest development way. Under the influence of a variety of reasons, the situation of succession of Zhuxian Town woodcut new year paintings is not going well, which urgently needs to carry out comprehensive study by taking advantage of the modern digital technology, so as to lay a solid foundation for the industrialization development.

\section{B. Digital Interpretation Is the Need for Its Inheritance and Development}

Compared with the traditional means, the advantage of digital technology is obvious. The first is the truth. Use digital imaging technology to carry out the most authentic records to the New Year paintings and the relevant activities, which can be played and researched in repeatedly. The second is the intuitiveness. Digital technology can directly transfer the relevant issues to the public in the audio-visual combination way, which is easier for audience to recognize and accept. The third is the permanency. Some data can be preserved in a long-term manner after becoming the digital materials, which cannot be compared by the traditional text, oral recording and other way. The fourth is the transmissibility. After becoming the digital materials, with the help of digital equipment, it can achieve infinite propagation in a very short period of time, and the cost is very low. So, through the use of digital technology, it can promote the inheritance and development of Zhuxian Town woodcut New Year paintings essentially.

\section{The Advantage of Digital Interpretation of Zhuxian Town Woodcut New Year Paintings}

Digital art is a new art form. Multimedia technology combines image, sound, text, animation, audio and even the smell and a variety of forms of communication together, to 
enrich the art language and the form of expression, improve the appeal of the work.

Virtual reality is an advanced man-machine interface with simulation of human visual, auditory, tactile and other sensory functions, which can make people be immersed in the virtual world with visual, auditory, tactile and other feelings generated by computer, to achieve real-time interaction with computer through language, gestures, body movements, sight movement and other ways, which is the same as the realistic feeling.. It can not only simulate the reality, but also reconstruct the monuments, and even the unreal world, so that people can feel the experience which can not personally experienced. Virtual reality can fully satisfy the performance of art creation to feeling and provide more creative freedom for artists and designers. At present, the common virtual reality software is QuickDraw3D, VRML, Metastream, 3DDreams, QTVR, Cult3D, etc.. Such as Apple's QuickDraw3D can implement drag of three-dimensional geometry body in the window to carry out any angle of observation, but also transform the lighting, materials, etc., which makes the display of three-dimensional objects very convenient.

Digital art can take inspiration and material from the folk art, such as applying the exaggeration and distortion of folk art in digital art design to achieve the vivid effects. At the same time, it can also reflect the national characteristics of the design. The digital art due to the adoption of digital technology with powerful function, can provide a vast garden of creation for folk art, at the same time, some special effects of digital technology can also be applied directly to the folk art, so as to promote the development of folk art.

\section{ThE GRASP OF FOLK ART AND CULTURAL CONNOTATION IN Digital ART DESIGN}

Digital technology promotes the development of digital art and design, enhances the artistic expressive force, but with the development of modern civilization and the improvement of people's aesthetic accomplishment, audience's art appreciation not only stays in a strong visual experience, but pays more attention to requirements of higher spiritual level, namely, art needs to touch people's heart. Therefore, to simply focus on the digital technology to enhance the visual impact of art will no longer attract the audience, while the artistic character and cultural connotation will more strongly influence the audience's aesthetic taste, so creative design of digital art will gradually transfer to the deep level of humanistic connotation. The word says that "the humanities refer to various cultural phenomenon of the human society". It includes culture, art, aesthetics, education, philosophy, culture and history. In order to reflect the characteristics of cultural connotation, for the design of digital art, in addition to the study of the external form of the design, we shall also pay more attention to the grasp of cultural connotation of folk art, pay attention to the understanding of traditional Chinese values, ethics, and put the understanding into the design, to reflect the design soul.

\section{A. Grasp the Symbolic Language}

Folk art has a rich connotation, with many symbolic shapes. Such as: the New Year paintings "Mashang fenghou", "Lotus", cabbage to represent "Baicai" of homophonic Chinese, bat to represent "Fu" of homophonic Chinese. Theses symbolic shapes with their profound connotation and beautiful meaning for people to inherit, become one part with the most aesthetic value in folk art form. In the design of modern digital art, it can also adopt this symbolic metaphorical method, use the technology of computer software, which can make the abstract concept convert into concrete images, and make the graph more vivid, more convincing.

\section{B. Reflect the Value of Ethics}

The reflection of a large number of ethical and moral values in the works of folk art. The Changban Slope, Nine Dragons Mountain, Sanniang Teaches Son, Five Children Later in Life and other themes in Zhuxian Town woodcut new year paintings all promote the traditional "loyalty, filial piety, benevolence, love, faithfulness, generosity" concept, which is influenced by the traditional Confucian thoughts, on the other hand, it reflects the people's high acceptance of the thoughts after digestion and absorption. In addition, the value orientation of Chinese traditional culture is based on family, that pays attention to the family, community relations, family affection, the happiness of family union, deep feelings for family. The warmth and harmoniousness of family is the understanding of Chinese of the ideal family. The digital art design to reflect the traditional humanistic content should pay attention to the integration of traditional values.

\section{Highlight the Folk Customs}

National or ethnic members of society have worked together to create folk customs, and passed on from generation to generation to form the phenomenon of culture life, which is a part of social life, also the foundation and the main content of national culture. There are a large number of folk festivals depictions in the New Year paintings and other folk arts. Digital art design can start with the elements of folk art, the theme and the significance of folk customs, reflecting the connotation of traditional culture.

\section{DigITAL INTERPRETATION OF ZHUXIAN TOWN WOODCUT NEW YEAR PAINTINGS UNDER THE BACKGROUND OF INDUSTRIALIZATION}

\section{A. Establish Information Database}

Above mentioned, the full integration of all kinds of information of Zhuxian Town woodcut New Year paintings is the foundation of industrialization development, also the needs of the inheritance and development. In the highly developed digital technology today, it is supposed to establish an information database to achieve the above two purposes. Specifically, the information database mainly contains the following modules. The first is the information acquisition module. The information here is mainly the text information of Zhuxian Town woodcut new year paintings, including development history, representatives, representative works, 
cultural sites, making process etc. The preservation in digital form can effectively avoid paper and oral records of easy loss. Followed by the digital resource processing module, includes digital photo shoot, digital recording, video production, threedimensional effects, etc. In other words, through the digital resources processing, it is possible to reproduce the real true state of the production, circulation, appreciation and other various activities of Zhuxian Town woodcut New Year paintings. Then it is the management module. Management module mainly refers to the input management and column settings etc. of information database. Through effective management, it can make all kinds of resources present in front of audience with more systematic and coherent appearance. The last one is the release module. The information in the database is not static, but closely linked with the development of Zhuxian Town woodcut New Year paintings. Whenever there is new information, the database should be timely included and update. Through the establishment of the database, it can give researchers, developers and others with great convenience, which is a power and event in the contemporary, and in future generations.

\section{B. Open Special Website}

The 21 st century is undoubtedly a network era. Through the network, it can release information to the world and communicate in a very short period of time, so the establishment of the Zhuxian Town woodcut New Year paintings website is particularly necessary. The site should contain the following contents: the text data of Zhuxian Town woodcut new year paintings, through reading the text and picture information to help the audience have a comprehensive cognition and understanding; the second is to display some of the audio and video data, which contains historical and contemporary all kinds of audio and video data of Zhuxian Town woodcut new year paintings, through the listening and watching of information to help deepen and enrich the former feelings. The third is the settings of experience zone. Using 3D virtual imaging technology to create a real scene of making New Year paintings, that the audience can participate in the making process of New Year paintings in the identity of the producers, also is able to demonstrate and evaluate their works, in the form of a kind of interest to attract more people's attention. The fourth is the establishment of interactive forum. Specially design message boards, forums and other sections, where all people can speak freely, to become a stronghold for all kinds of people who are concerned about Zhuxian Town woodcut New Year paintings. Website managers should pay attention to all kinds of information timely, and actively accept some constructive suggestions. And in the process of industrialization, the birth of a number of new industrial projects shall also be presented in the form of special topics on the site, in order to truly advance with the times. Through the establishment of the website, really establish a network camp for all open, shorten the distance between the New Year paintings art and the ordinary people, so that they can appreciate the unique charm of Zhuxian Town woodcut new year paintings in more convenient and intuitive ways.

\section{Integrate with Other Digital Industries}

On April 5, 2010, CCTV news network had emphatically introduced a new year painting named as Beautiful, Folk Yangjiabu, which is a new animation through the comprehensive study of the raw materials of 10 Bustling of Men, 10 Bustling of Women, the Champion Wedding and other works in Yangjiabu new year paintings. Once on display, it was universally acclaimed. From the point of view of digitalization and industrialization development of New Year paintings, combining with the animation industry is undoubtedly a win-win strategy. Animation art has gained new vitality due to the integration of the new elements, while New Year paintings also have found a new way of inheritance with animation and opened up a new industrial project. And as the Zhuxian Town woodcut New Year paintings, equally famous as Yangjiabu New Year paintings, can also be combined with animation industry. From the subject matter, with very wide contents, it is an important expression carrier of folk culture, and has a good meaning of auspicious. Although not necessarily suitable for direct application in the animation works, but after processing and extraction, it can be an important source of animation. From the formal point of view, the rustic style of Zhuxian Town woodcut New Year paintings has a strong local flavor. The color also accords with traditional customs, bright but not light. The picture composition is density, unity in diversity, which is a kind of important reference for Jiugong format type animation composition. Therefore, the organic combination of the animation and New Year paintings is undoubtedly a valuable exploration. In the times of the digital technology highly developed, to produce the feature animation of Zhuxian Town woodcut New Year paintings is not only the enriching of Chinese animation, but also the birth of a new industrial project.

\section{Establish the Perfect Protection Mechanism}

Digital interpretation and industrial development, is not a kind of idea and slogan, but a work needing to push forward solidly. So it needs to establish a solid security mechanism. The first is to improve the construction of functional departments. Due to the current situation of lacking unified organization and management and responsibility not implemented in place, it is necessary to set up provincial and municipal administration, responsible for the overall construction of the project, to ensure that the work of the project can be implemented in normal and orderly manner. The second is to increase the investment of funds. Governments at all levels and departments should set up special funds to support the digitalization and industrialization development of New Year paintings. Under the circumstances of limited government investment, it can actively introduce folk capital, to jointly build the New Year paintings cultural industry fund. On the one hand, it can provide the most direct financial support for a number of high-quality projects, resulting in new growth models and growth points; on the other hand, those projects valued by the fund can be said as the vane of the development of the whole industry, which can play the exemplary role, to achieve the positive effect of transference. Finally increase the intensity of personnel training. On the one hand, the relevant functional departments 
should establish positive relationship with the local colleges and universities, select the related professionals of the colleges, train the personnel needed in the digitalization and industrialization development of new year paintings with special training method; on the other hand, carry out regular training of existing staff, to constantly improve their information technology, so as to guarantee the digitalization quality. Through the construction of management, capital and personnel, provide the most solid guarantee to Zhuxian Town woodcut New Year paintings in the construction of industrialization and digitalization, to ensure that all work always are promoted step by step in a healthy and orderly direction.

\section{CONCLUSION}

In summary, after entering the twenty-first century, the scale of cultural industrialization is getting bigger and bigger, and the significance and value of it has been gradually recognized. As one of the traditional cultures, Zhuxian Town woodcut New Year paintings should also actively join the ranks of the industrialization. And from a practical point of view, to promote the digital construction and development, is the foundation of the industrialization road, also the fittest channel of its essential characteristics, both to enable the spread and inheritance, but also to get enormous economic benefits and social benefits. This paper is based on this purpose, to carry out specific analysis, hoping to cast a brick to attract jade, and give the inspiration and reference to more people.

\section{References}

[1] Xu Limin. The Preservation, Inheritance and Development ofZhuxian Town Woodcut New Year Paintings [J]. Journalism \& Communication. 2010 (12).

[2] Yu Huijian. The Composition and Status of Zhuxian Town WoodcutNew Year Paintings Art Industry Chain[J]. Journal of Zhongzhou University. 2009 (02).

[3] [US] Written by Gloria, translated by Hu Yong et al. Being Digital. Hainan Press, 1997.

[4] Wang Shucun, Wang Haixia. New Year Paintings. Zhejiang People's Publishing House, 2005.3.

[5] Deng Fuxing. An Introduction to Chinese Folk Fine Arts. Heilongiiang Press, 2003.3. 